\title{
Perimesencephalic Nonaneurysmal Subarachnoid Hemorrhage Caused by Physical Exertion
}

\author{
Takeshi MatsuYama, Kazuo OKUCHI, Tadahiko SEKI, \\ Takafumi HigUCHI, and Yoshinori MURAO
}

Department of Critical Care and Emergency Medicine, Nara Medical University, Kashihara, Nara

\begin{abstract}
The clinical characteristics of perimesencephalic nonaneurysmal subarachnoid hemorrhage (SAH) caused by physical exertion were analyzed to investigate the causes and mechanisms of perimesencephalic nonaneurysmal SAH. Nine of 209 patients with spontaneous SAH were identified as having perimesencephalic nonaneurysmal SAH. Perimesencephalic nonaneurysmal SAH in four males and three females was precipitated by exertion. Age, sex predominance, type of exertion, symptoms, loss of consciousness during bleeding, clinical grade, angiographic spasm, hydrocephalus, delayed ischemic deficit, rebleeding, hypertension, and outcome were evaluated in these seven patients. Outcomes were assessed using the Glasgow Outcome Scale. Patients showed male predominance $(57.1 \%)$, relatively young age (mean 50 years), low frequency of hypertension $(28.6 \%)$, good clinical grade (World Federation of Neurological Surgeons grade I or II), and excellent outcomes including no rebleeding, no symptomatic hydrocephalus, and no delayed ischemic deficits. The type of exertion was swimming in two patients, golfing in two patients, heavy lifting in two patients, and bending forward during gymnastics in one patient. Physical exertion including components of the Valsalva maneuver is an important predisposing factor for perimesencephalic nonaneurysmal SAH. Such physical exertion produces increased intrathoracic pressure, which blocks the internal jugular venous return, resulting in elevated intracranial venous pressure or mechanical swelling of the intracranial veins, and leads to venous or capillary breakdown.
\end{abstract}

Key words: perimesencephalic nonaneurysmal subarachnoid hemorrhage, physical exertion

\section{Introduction}

Spontaneous subarachnoid hemorrhage (SAH) occurs without abnormal angiographical findings in about $10-20 \%$ of patients, suggesting the absence of aneurysmal bleeding or other vascular anomalies. ${ }^{18,19)}$ Perimesencephalic nonaneurysmal SAH accounts for $21-68 \%$ of such nonaneurysmal SAH. ${ }^{16)}$ Originally, perimesencephalic nonaneurysmal SAH was defined as hemorrhage centered around the mesencephalon, with or without extension of blood to the anterior part of the ambient cistern or basal part of the sylvian fissure, without complete filling of the anterior interhemispheric fissure or extension to the lateral sylvian fissure, except for minute amounts of blood, and absence of frank intraventricular hemorrhage. ${ }^{11)}$ Recently, computed tomography (CT) and magnetic resonance (MR) imaging

Received May 10, 2004; Accepted December 27, 2005 have revealed that perimesencephalic nonaneurysmal SAH is located just anterior to the brainstem, so the term pretruncal nonaneurysmal SAH has been suggested. ${ }^{14)}$ The diagnosis and clinical course of perimesencephalic nonaneurysmal SAH have been extensively investigated. ${ }^{1-3,5,9,10,16,17,19)}$ However, the cause and mechanisms of such bleeding remain unclear.

Here we describe seven cases of perimesencephalic nonaneurysmal SAH caused by physical exertion, with six of seven cases bleeding at a pretruncal site.

\section{Subjects and Methods}

A total of 209 patients with spontaneous SAH were consecutively admitted to our department between January 1992 and December 2003. Patients were selected based on the following factors: Angiography showed no abnormality; initial CT revealed perimesencephalic nonaneurysmal $\mathrm{SAH}$ as defined previously ${ }^{19)}$; and the symptoms were precipitated 
Table 1 Patient profiles

\begin{tabular}{|c|c|c|c|c|c|c|c|c|c|c|}
\hline $\begin{array}{l}\text { Case } \\
\text { No. }\end{array}$ & Sex & $\begin{array}{l}\text { Age } \\
\text { (yrs) }\end{array}$ & $\begin{array}{l}\text { Follow-up } \\
\text { period } \\
\text { (mos) }\end{array}$ & $\begin{array}{l}\text { Hyper- } \\
\text { tension }\end{array}$ & Symptoms & $\begin{array}{l}\text { Clinical } \\
\text { grade } \\
\text { (WFNS) }\end{array}$ & $\begin{array}{l}\text { Physical } \\
\text { exertion }\end{array}$ & $\begin{array}{l}\text { Angiographic } \\
\text { findings } \\
\text { (initial/repeat) }\end{array}$ & $\begin{array}{l}\text { Hydro- } \\
\text { cephalus }\end{array}$ & Outcome \\
\hline 1 & $\mathrm{~F}$ & 52 & 35 & yes & severe headache & II & swimming & normal/normal & no & excellent \\
\hline 3 & M & 47 & 62 & no & nausea, vomiting & I & $\begin{array}{l}\text { heavy } \\
\text { lifting }\end{array}$ & normal/normal & no & excellent \\
\hline 4 & $\mathrm{M}$ & 58 & 38 & yes & severe headache & I & $\begin{array}{l}\text { bending } \\
\text { forward }\end{array}$ & $\begin{array}{l}\text { slight spasm/ } \\
\text { normal }\end{array}$ & yes & excellent \\
\hline 6 & $\mathrm{~F}$ & 55 & 75 & no & $\begin{array}{l}\text { mild headache, } \\
\text { vomiting }\end{array}$ & II & $\begin{array}{l}\text { heavy } \\
\text { lifting }\end{array}$ & normal/normal & no & excellent \\
\hline 7 & M & 46 & 54 & no & severe headache & II & golfing & $\begin{array}{l}\text { slight spasm/ } \\
\text { normal }\end{array}$ & no & excellent \\
\hline
\end{tabular}

WFNS: World Federation of Neurological Surgeons.

by physical exercise. The diagnosis of SAH was verified by CT. Criteria for perimesencephalic nonaneurysmal SAH were as follows: Center of bleeding located anterior to the midbrain, with or without extension of blood to the anterior section of the ambient cistern or basal section of the sylvian fissure; no extension to the anterior interhemispheric fissure, except for a small amount of blood; and absence of frank intraventricular hemorrhage. All patients underwent four-vessel cerebral angiography. Repeat angiography was performed after 2 and 4 weeks when the first angiography was normal or showed vasospasm.

Clinical grade was evaluated according to World Federation of Neurological Surgeons (WFNS) definitions. The patients were treated symptomatically. Analgesics, laxatives, tranquilizers, and strict bed rest for 10-14 days were prescribed. Outcomes were assessed using the Glasgow Outcome Scale. Age, sex predominance, past history of hypertension, symptoms, type of physical exertion, clinical grade, angiographic spasm, presence of hydrocephalus, outcome, and CT findings were evaluated.

\section{Results}

Perimesencephalic nonaneurysmal SAH was identified in nine of the 209 patients with spontaneous $\mathrm{SAH}$. Perimesencephalic nonaneurysmal SAH was precipitated by physical exertion in seven of the nine patients, four males and three females aged 43 to 58 years (mean 50 years) (Table 1). Only two patients $(28.6 \%)$ had a history of hypertension. No patient suffered from loss of consciousness during the attack. All patients were in WFNS grade I or II. Initial CT was performed within 8 hours of the attack in all patients (Table 2). Slight diffuse spasm in the anterior circulation was recognized 2 weeks
Table 2 Computed tomography findings of perimesencephalic nonaneurysmal subarachnoid hemorrhage

\begin{tabular}{|c|c|c|c|c|}
\hline $\begin{array}{l}\text { Case } \\
\text { No. }\end{array}$ & $\begin{array}{l}\text { Location of } \\
\text { center of } \\
\text { bleeding }\end{array}$ & $\begin{array}{l}\text { Thick- } \\
\text { ness }\end{array}$ & $\begin{array}{l}\text { Extension of } \\
\text { hemorrhage }\end{array}$ & $\begin{array}{l}\text { Interval } \\
\text { to } \\
\text { washout } \\
\text { (days) }\end{array}$ \\
\hline 1 & $\begin{array}{l}\text { prepontine } \\
\text { cistern }\end{array}$ & thick & $\begin{array}{l}\text { interpeduncular, } \\
\text { crural, and } \\
\text { quadrigeminal } \\
\text { cisterns }\end{array}$ & 10 \\
\hline 2 & $\begin{array}{l}\text { prepontine } \\
\text { cistern }\end{array}$ & thin & $\begin{array}{l}\text { interpeduncular } \\
\text { and crural } \\
\text { cisterns }\end{array}$ & 7 \\
\hline 3 & $\begin{array}{l}\text { interpeduncular } \\
\text { cistern }\end{array}$ & thin & crural cistern & 3 \\
\hline 4 & $\begin{array}{l}\text { prepontine } \\
\text { cistern }\end{array}$ & thick & $\begin{array}{l}\text { interpeduncular, } \\
\text { crural, and } \\
\text { quadrigeminal } \\
\text { cisterns, } \\
\text { sylvian } \\
\text { valleculla }\end{array}$ & 13 \\
\hline 5 & $\begin{array}{l}\text { quadrigeminal } \\
\text { cistern }\end{array}$ & thin & $\begin{array}{l}\text { supracerebellar } \\
\text { cistern }\end{array}$ & 5 \\
\hline 6 & $\begin{array}{l}\text { prepontine } \\
\text { cistern }\end{array}$ & thin & $\begin{array}{l}\text { interpeduncular, } \\
\text { crural, and } \\
\text { premedullary } \\
\text { cisterns }\end{array}$ & 7 \\
\hline 7 & $\begin{array}{l}\text { interpeduncular } \\
\text { cistern }\end{array}$ & thin & $\begin{array}{l}\text { prepontine } \\
\text { cistern }\end{array}$ & 6 \\
\hline
\end{tabular}

after the attack in two patients, but delayed ischemic deficits were identified as complications. Acute hydrocephalus was recognized in one patient (Case 4), but no shunt operation was necessary. No patient suffered rebleeding during the follow-up period. Outcomes were excellent in all patients.

\section{Representative Case}

Case 1: A 52-year-old woman was admitted to a local hospital complaining of sudden onset of severe headache in June 2000. The symptoms had occurred 


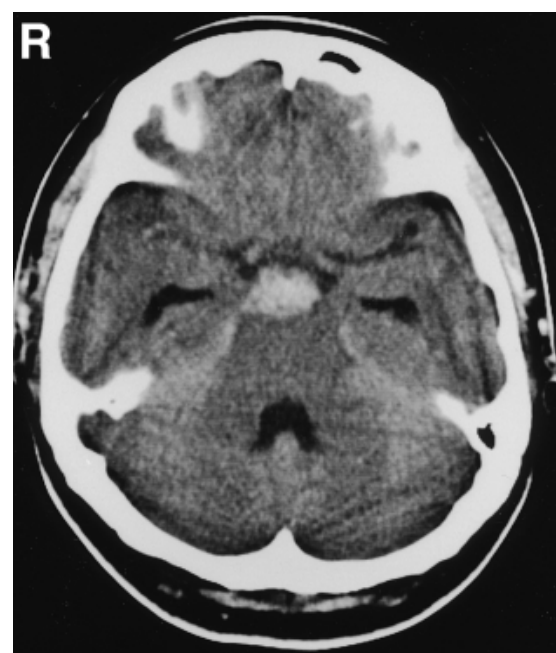

Fig. 1 Case 1. Computed tomography scan revealing a small area of slight hyperdensity in the interpeduncular cistern just anterior to the pons.

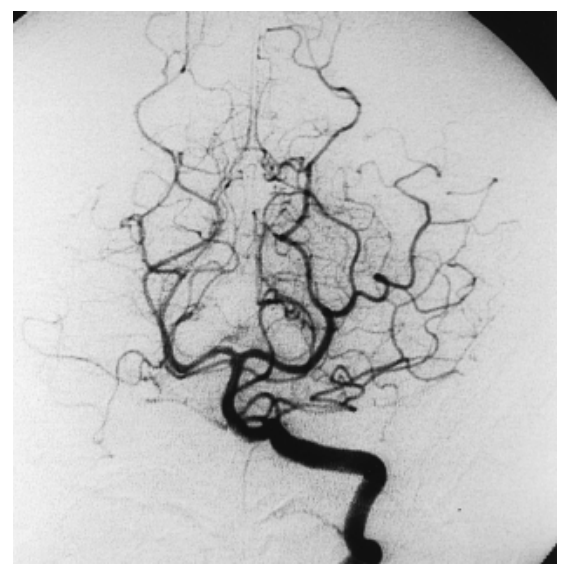

Fig. 2 Case 1. Left vertebral angiogram showing no abnormal findings such as aneurysms or other vascular anomalies.

during abrupt extreme hyperextension of the neck while swimming. Headache was generalized and throbbing, and associated with nausea and vomiting. On admission, the patient was alert with no neurological deficits. Slight nuchal rigidity was apparent. Clinical grade was II. Pupils were isocoric and reacted normally to light. CT revealed a small area of slight hyperdensity in the interpeduncular cistern just anterior to the pons, suggesting $\mathrm{SAH}$ (Fig. 1). She was transferred to our department for further treatment. Cerebral angiography performed immediately after admission revealed no abnormal findings such as aneurysms or other vascular anomalies (Fig. 2). The patient was treated conservative-

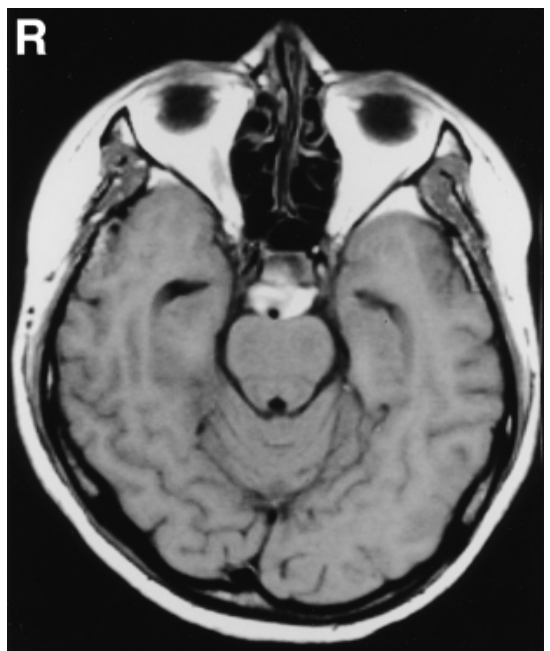

Fig. 3 Case 1. $T_{1}$-weighted magnetic resonance image revealing a high-intensity mass just ventral to the midbrain and pons.

ly with control of blood pressure. Seven days after admission, repeat angiography showed no abnormalities. $\mathrm{T}_{1}$ - and $\mathrm{T}_{2}$-weighted MR imaging revealed a high-intensity mass just ventral to the midbrain and pons (Fig. 3). The hematoma was limited to the posterior of the basal cistern. The patient showed no neurological exacerbation. Nine days after admission, she was discharged with no neurological deficits.

\section{Discussion}

A clinical review of 174 cases of perimesencephalic nonaneurysmal SAH found that the patients are more likely to be younger (mean age 50.1 years) males (52-59\%) without hypertension (3-20\%) compared to patients with aneurysmal SAH. ${ }^{16)}$ In addition, all patients were Hunt and Hess grade I or II. Outcomes were excellent in all 174 patients, and rebleeding during follow up was not reported. Symptomatic hydrocephalus requiring shunt operation occurred in $1 \%$ of patients, and vasospasm in $1-5 \%$. No rebleeding was experienced after discharge. Delayed cerebral severe diffuse spasm was identified in only two patients with perimesencephalic nonaneurysmal SAH. ${ }^{15)}$ Transient amnesia was identified in approximately one-third of patients. ${ }^{4)}$ Our patients showed male predominance (57.1\%), relatively young age (mean 50 years), low frequency of hypertension $(28.6 \%$ ), good clinical grade (WFNS grade I or II), and excellent outcomes including no rebleeding, no symptomatic hydrocephalus, and no delayed ischemic deficits. 
The cause of perimesencephalic nonaneurysmal SAH may be venous or capillary bleeding anterior to the brainstem. ${ }^{11,19)}$ Tearing of the basal vein of Rosenthal or a tributary has also been proposed as a bleeding source. Tearing of these veins is caused by external forces such as torsion or friction against the tentorial edge, or abrupt swelling due to increases in intrathoracic pressure. The clinical aspects of perimesencephalic nonaneurysmal SAH indicate a lesser impact compared to aneurysm rupture, given the infrequent loss of consciousness and slow onset of headache. ${ }^{19)}$ Abnormal venous drainage was found in six patients with perimesencephalic nonaneurysmal SAH. ${ }^{20}$ The basal vein of Rosenthal in patients with perimesencephalic nonaneurysmal SAH generally (58\%) drains into the dural sinuses (cavernous sinus via the uncal vein, superior petrosal sinus, or tentorial sinus) instead of the galenic vein. Intracranial venous congestion caused by straining, or sudden swelling of the tributaries of the basal vein of Rosenthal in patients with anomalous venous drainage, might tear a vein fixed to a dural sinus. ${ }^{20)}$ The anterior pontomesencephalic, interpeduncular, or posterior communicating veins are other potential bleeding sources. ${ }^{11)}$ A small bulge detected on the posterior surface of basilar artery in one case may have indicated entry to the intramural hematoma cavity due to arterial dissection. ${ }^{6)}$ Perimesencephalic nonaneurysmal SAH also may be caused by rupture of an intramural hematoma and spontaneous healing of the adventitia.6,13)

Exertional headache is precipitated by physical activity. The primary mechanism is the Valsalva maneuver, caused by exhaling forcibly against a closed glottis. Any stimuli like the Valsalva maneuver, such as coughing, laughing, bending, and exercising, produces increased intrathoracic pressure that blocks the internal jugular venous return, causing elevated intracranial venous pressure and subsequent elevated intracranial pressure. ${ }^{8)}$ Exertional headaches are benign in $80 \%$ of patients and symptomatic in $20 \% .{ }^{12)}$ Benign exertional headache is not associated with systemic or intracranial disorders. Conversely, symptomatic exertional headache is associated with structural brain lesions, most frequently Arnold-Chiari malformation, intracranial mass in the posterior fossa, basilar impression, platybasia, sinus disease, and SAH. Investigation of 28 patients with headache precipitated by physical exercise found that 16 patients displayed benign exertional headaches and 12 patients had symptomatic exertional headaches.7) The cause of headache was SAH in 10 patients, pansinusitis in one patient, and multiple brain metastases in one patient. All patients with SAH underwent cerebral angiography. Aneurysmal SAH was identified in only two patients. SAH of unknown origin was found in the remaining eight patients. ${ }^{7)}$ Some of these eight patients probably had perimesencephalic nonaneurysmal SAH. This study suggested that further investigation of the potential cause of headache is necessary, as patients with lifethreatening aneurysmal SAH might present with exertional headache.

Physical exertion has caused 11 cases of perimesencephalic nonaneurysmal SAH. Analysis of the clinicoradiological features in 28 patients with SAH due to ruptured posterior circulation aneurysm and 44 patients with perimesencephalic nonaneurysmal $\mathrm{SAH}^{1)}$ found that symptoms were precipitated by straining or vigorous physical activity in only two of the 28 patients with aneurysmal SAH, in contrast to seven of 44 patients with perimesencephalic nonaneurysmal SAH. Symptoms were caused by physical stress such as tooth extraction, coughing, swimming, or turning the face downward in four of six patients with perimesencephalic nonaneurysmal SAH. ${ }^{20)}$

Perimesencephalic nonaneurysmal SAH caused by physical exertion was identified in seven of our nine patients with perimesencephalic nonaneurysmal SAH. This incidence seems to be higher than previously reported but does indicate a relationship between physical exertion and perimesencephalic nonaneurysmal SAH. Strenuous physical activities including breath holding during swimming, bending forward in gymnastics, heavy lifting, and swinging while golfing all caused perimesencephalic nonaneurysmal SAH. Such physical exertion produces increased intrathoracic pressure, which blocks the internal jugular venous return, resulting in elevated intracranial venous pressure or mechanical swelling of the intracranial veins, and leads to venous or capillary breakdown. We suggest that physical exertion including components of the Valsalva maneuver is an important predisposing factor for perimesencephalic nonaneurysmal SAH.

\section{References}

1) Alen JF, Lagares A, Lobato RD, Gomez PA, Rivas JJ: Comparison between perimesencephalic nonaneurysmal subarachnoid hemorrhage and subarachnoid hemorrhage caused by posterior circulation aneurysms. J Neurosurg 98: 529-535, 2003

2) Canhäo P, Ferro JM, Pinto AN, Melo TP, Campos JG: Perimesencephalic and nonperimesencephalic subarachnoid haemorrhages with negative angiograms. Acta Neurochir (Wien) 132: 14-19, 1995

3) Cioffi F, Pasqualin A, Cavazzani P, Da Pian R: Subarachnoid haemorrhage of unknown origin: 
Clinical and tomographical aspects. Acta Neurochir (Wien) 97: 31-39, 1989

4) Hop JW, Bristla EH, Rinkel GJE: Transient amnesia after perimesencephalic hemorrhage: The role of enlarged temporal horns. J Neurol Neurosurg Psychiatry 65: 590-593, 1998

5) Ildan F, Tuna M, Erman T, Gocer AI, Cetinalp E: Prognosis and prognostic factors in nonaneurysmal perimesencephalic hemorrhage: a follow-up study in 29 patients. Surg Neurol 57: 160-165, 2002

6) Matsumaru Y, Yanaka K, Muroi A, Sato H, Kamezaki $\mathrm{T}$, Nose T: Significance of a small bulge on the basilar artery in patients with perimesencephalic nonaneurysmal subarachnoid hemorrhage. Report of two cases. J Neurosurg 98: 426-429, 2003

7) Pascual J, Iglesias F, Oterino A, Vazquez-Barquero A, Berciano J: Cough, exertional, and sexual headaches: an analysis of 72 benign and symptomatic cases. Neurology 46: 1520-1524, 1996

8) Queiroz LP: Symptoms and therapies: exertional and sexual headaches. Curr Pain Headache Rep 5: 275-278, 2001

9) Rinkel GJE, Wijdicks EFM, Hasan D, Kienstra GEM, Franke CL, Hageman LM, Vermeulen M, van Gijn J: Outcome in patients with subarachnoid haemorrhage and negative angiography according to pattern of haemorrhage on computed tomography. Lancet 338: 964-968, 1991

10) Rinkel GJE, Wijdicks EFM, Vermeulen M, Hasan D, Brouwers PJAM, van Gijn J: The clinical course of perimesencephalic nonaneurysmal subarachnoid hemorrhage. Ann Neurol 29: 463-468, 1991

11) Rinkel GJE, Wijdicks EFM, Vermeulen M, Ramos LMP, Tanghe HLJ, Hasan D, Meiners LC, van Gijn J: Nonaneurysmal perimesencephalic subarachnoid hemorrhage: CT and MR patterns that differ from aneurysmal rupture. AJNR Am J Neuroradiol 12: 829-834, 1991

12) Sands GH, Newman L, Lipton R: Cough, exertional, and other miscellaneous headaches. Med Clin North Am 75: 733-747, 1991

13) Schievink WI, Wijdicks EF: Origin of pretruncal nonaneurysmal subarachnoid hemorrhage: ruptured vein, perforating artery, or intramural hematoma? Mayo Clin Proc 75: 1169-1173, 2000

14) Schievink WI, Wijdicks EFM: Pretruncal subarachnoid hemorrhage: an anatomical correct description of the perimesencephalic hemorrhage. Stroke 28: 2572, 1997

15) Schievink WI, Wijdicks EFM, Spetzler RF: Diffuse vasospasm after pretruncal nonaneurysmal subarachnoid hemorrhage. AJNR Am J Neuroradiol 21: 521-523, 2000

16) Schwarz TH, Solomon RA: Perimesencephalic nonaneurysmal subarachnoid hemorrhage: Review of the literature. Neurosurgery 39: 433-440, 1996

17) Van Calenbergh F, Plets C, Goffin J, Velghe L: Nonaneurysmal subarachnoid hemorrhage: prevalence of perimesencephalic hemorrhage in a consecutive series. Surg Neurol 39: 320-323, 1993
18) van Gijn J, van Dongen KJ: Computerized tomography in subarachnoid hemorrhage: difference between patients with and without an aneurysm on angiography. Neurology 30: 538-539, 1980

19) van Gijn J, van Dongen KJ, Vermeulen M, Hijdra A: Perimesencephalic hemorrhage: a nonaneurysmal and benign form of subarachnoid hemorrhage. Neurology 35: 493-497, 1985

20) Watanabe $A$, Hirano $K$, Kamada M, Imamura K, Ishii N, Sekihara Y, Suzuki Y, Ishii R: Perimesencephalic nonaneurysmal subarachnoid haemorrhage and variations in the veins. Neuroradiology 44: 319-325, 2002

Address reprint requests to: T. Matsuyama, M.D., Department of Critical Care and Emergency Medicine, Nara Medical University, 840 Shijo-cho, Kashihara, Nara 634-8522, Japan.

\section{Commentary}

Exertion and its speculative mechanisms have been invoked in association with aneurysmal subarachnoid hemorrhage (SAH), reported during a variety of physical stresses, sexual activity, and even choir singing. ${ }^{1)}$ Matsuyama and colleagues here report physical exertion preceding nonaneurysmal perimesencephalic SAH in 7 of 9 consecutive cases. They offer mechanisms related to Valsalva maneuver, causing venous hypertension, and this in turn could predispose to venous bleeding that had been postulated in many of these cases. This would be a different mechanism than that causing aneurysmal SAH, where transmural pressure across a vulnerable aneurysm is likely at play.

Such high association is certainly notable, but not definitive nor certain. It is not clear how the history of exertion was evoked in these cases, and whether this was standardized or could have reflected a bias by suggestingly "leading the patient" toward the doctors' hypothesis. It is also unclear if history of exertion was similarly sought in aneurysmal SAH and in nonperimesencephalic nonaneurysmal SAH cases, and what the prevalence of exertion association in those, when history is similarly sought in a controlled fashion, and preferably by a blinded adjudicator. The number of cases is small, and correlations of exertion with time of onset of SAH symptoms, and the nature of exertion could not easily be analyzed nor compared among SAH subtypes.

The mechanisms of perimesencephalic nonaneurysmal SAH remain a mystery, and the unique characteristics of this disease will only be elucidated by a thorough and precise analysis of clinical and anatom- 
ic risk factors involving the host, and extrinsic and exacerbating factors such as exertion. The authors are congratulated for raising awareness about this entity, reviewing its very confusing literature, and invoking new hypotheses to be tested in future studies.

\section{Reference}

1) Mayer P, Awad IA: Subarachnoid hemorrhage and choir singing. J Neurosurg 81: 159, 1994 (letter)

Issam A. AWAD, M.D., M.Sc., F.A.C.S., M.A. (Hon.)

Evanston Northwestern Healthcare

Department of Neurological Surgery

Northwestern University

Feinberg School of Medicine

Evanston, Illinois, U.S.A.

When we operate in the perimesencephalic region, we may frequently notice how fragile small arterioles or tiny veins can be in this area, at least in some patients. It is, therefore, understandable that physical exertion such as sudden head movement or Valsalva maneuver may occasionally cause rupture of these tiny vessels resulting in the typical perimesencephalic nonaneurysmal subarachnoid hemorrhage (SAH). This report is a valuable contribution to our knowledge about the incidence and the underlying mechanism of this type of SAH. The authors have meticulously analyzed a large patient population and were able to demonstrate a relatively high incidence of nonaneurysmal perimesencephalic SAH in individuals who were involved in strenuous physical activities.

Helmut BERTALANFFy, M.D. Department of Neurosurgery Philipps University Hospital Marburg, Germany

The authors report their experience with perimesencephalic nonaneurysmal subarachnoid hemorrhage (SAH) caused by physical exertion, and address the mechanism of this entity. Among the 209 patients with spontaneous $\mathrm{SAH}$, nine patients were diagnosed as perimesencephalic nonaneurysmal $\mathrm{SAH}$, and the seven subjects presented with symptoms caused by physical exertion. The subjects fulfilled the CT criteria of perimesencephalic nonaneurysmal SAH, and clinical characteristics were as follows: male predominance, relatively young age, low frequency of hypertension, good clinical grade at the time of onset, and excellent follow-up outcomes. They discuss roles of physical exertion through venous hypertension in perimesencephalic nonaneurysmal SAH. In clinical practice, we must consider that ruptured posterior circulation aneurysms or other aneurysms may present with the CT pattern of perimesencephalic SAH. Clinicoradiologic presentation of patients with perimesencephalic nonaneurysmal SAH is non-specific as compared with that of patients with aneurysmal SAH. The diagnosis of this entity should be established after the pertinent survey and exclusion of potentially life-threatening aneurysmal SAH.

Katsuyoshi Mineura, M.D. Department of Neurosurgery Kyoto Prefectural University of Medicine Kyoto, Japan

Perimesencephalic nonaneurysmal subarachnoid hemorrhage (PNSH), which has been named "Dutch disease," was first reported by von Gijin et al in 1985. Since then many prospective, retrospective, and case studies have reported worldwide, confirming the unique, benign nature of this particular subarachnoid hemorrhage. Dr. Matsuyama and his colleagues nicely reported 7 patients with PNSH and reviewed the relevant literature, focusing on the causes and the bleeding. They have identified physical exertion, including swimming, golfing, heavy lifting, and bending forward, as a major cause of this disease, which can produce intravenous hypertension, resulting in venous or capillary breakdown. This is a well-written article and authors have provided us with a very thoughtful study on the causes of PNSH.

We would like to congratulate the authors and emphasize the following. As repetition of angiography revealed pathological findings in $2-24 \%$ cases presenting with PNSH reported in the literature, appropriate angiography should be performed. In our practice, four-vessel cerebral angiography (bilateral internal carotid and vertebral angiography), is replaced by six-vessel cerebral angiography, bilateral internal carotid, external carotid and vertebral angiography, especially in cases with negative angiography. Some types of dural arteriovenous fistula could present with subarachnoid hemorrhage similar to PNSH.

Dong-lei Song, M.D. and Liang-Fu ZHOU, M.D. Department of Neurosurgery Institute of Neurology Hua Shan Hospital Fudan University Medical Center Shanghai, P.R.C. 